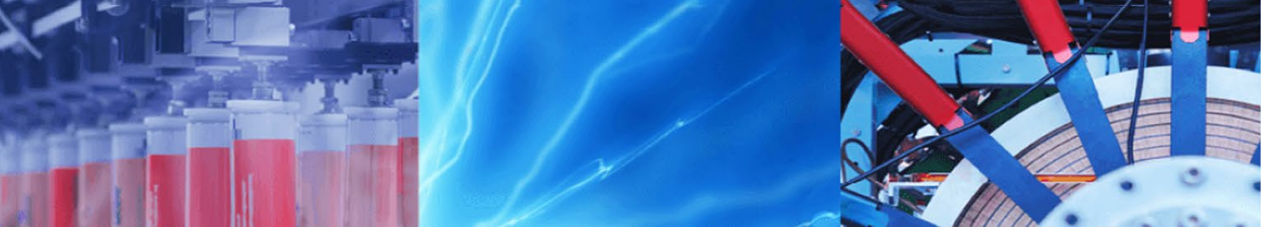

Research Article

\title{
Evaluation of adhesion and erosion/corrosion resistance of nano-composite and nano-multilayer thin films in molten aluminum alloy
}

\author{
F. Fazlalipour ${ }^{1}$ (I) M. Naghashnejad ${ }^{2} \cdot$ M. Niki Nushari $^{1}$ \\ (c) Springer Nature Switzerland AG 2019, corrected publication 2019
}

\begin{abstract}
Die casting as a well-known manufacturing method to produce high precision aluminum parts, encounters die failure. The most important wear and failure mode of die casting process is washout damage on working die surfaces attributed to erosion, corrosion, and soldering. Washout caused by a thermo-chemical interaction between aggressive aluminum melt and die steel on the surface. The influence of TiAIN-Si $\mathrm{N}_{4}$ nanocomposite and TiAIN/TiN nano-multilayer thin film coatings on washout resistance of $\mathrm{H}-13$ tool steel was evaluated in A384 aluminum alloy melt. Thin films were applied by physical vapor deposition using cathodic arc evaporation technique onto pre-nitrided pin-shape samples at $350^{\circ} \mathrm{C}$. $\mathrm{X}$-ray analysis was employed to assess films constitutive phases. Scanning electron microscopy (SEM) investigation and atomic force microscopy approach were employed to indicate surface morphology and roughness of nano-structural coatings. An accelerated immersion test was conducted to compare washout resistance of coated samples by immersion them in aluminum alloy melt for periods of $30,60,90$, and $120 \mathrm{~min}$ at $680^{\circ} \mathrm{C}$. Furthermore, specially developed release test was done to measure wettability and adhesion tendency of samples. SEM investigation of corroded and eroded surface showed some pitting effect on coatings and tribo-chemical interaction inside the pits between aluminum melt and substrate. Nano-structural coatings not only prevented intermetallic phase formation at the surface but also reduced the erosion/corrosion rate which is known as cause for the washout.
\end{abstract}

Keywords Nano-structural coating $\cdot$ Corrosion $\cdot$ Soldering aluminum melt $\cdot$ Die casting $\cdot$ TiAIN

\section{Introduction}

In aluminum high pressure die casting (HPDC) process, the dominant failure mechanism in die casting dies is washout caused by the combination of soldering, corrosion and erosion mechanisms [1-3]. During the filling and solidification stages, when bare surface of die steel is exposed to the molten metal, chemical reaction occurs between aluminum and steel as die substrate due to their chemical affinity. This reaction often results in formation of complex aluminum-iron-silicon intermetallic compounds at the die surface and soldering of the cast metal to the die $[4,5]$. The soldering and growth mechanisms of intermetallic compound layer have been investigated widely [6-14]. The diffusion of irons' atoms from the die into the molten alloy and the subsequent dissolution leads to gradual corrosion and formation of intermetallic layers and soldering. Erosive wear is defined as the gradual material removal from the surface of die. This takes place as a result of mechanical impingement of surface by aluminum melt when the high-speed molten aluminum is injected and forced into the die. This work investigated the overall effects of nanostructural coatings on aluminum melt wetting, soldering and corrosion and erosion resistance of die steel.

F. Fazlalipour, f.fazlali@gmail.com; M. Naghashnejad, mhmdnn@ou.edu; M. Niki Nushari, malahat.niki@gmail.com | ${ }^{1}$ R\&D Department of Iran Radiator Co. Ltd, Rasht 4165956581, Iran. ${ }^{2}$ School of Aerospace and Mechanical Engineering, University of Oklahoma, Norman, OK 73019 , USA.

SN Applied Sciences (2019) 1:1308 | https://doi.org/10.1007/s42452-019-1299-1 
In recent years, there has been a considerable progress in the development of Nanostructural coatings (hardness $\geq 40 \mathrm{GPa}$ ) $[15,16]$. These coatings are being developed as an attempt to replace the conventional PVD coatings, which are vulnerable to high-temperature applications. Nano-multilayer and nano-composite coatings of transition metal nitrides have received considerable interest due to their high hardness and wear resistance and the crack deflection qualities and thermal stability [8-12]. Therefore, these coatings have a great potential as protective coatings on cutting tools and die casting processes [17]. This research evaluates adhesion/wettability and erosion/corrosion performance of TiAIN/Si $\mathrm{N}_{4}$ nano-composite and TiAIN/TiN nano-multilayer coatings with working layers of TiN, TiAIN, which will be referred as NM-TiN, NM-TiAIN and NC coating respectively for the rest of the paper. In order to have comparative results, these three nano-structural coating systems were compared with two optimized commercial surface treatments including plasma nitriding, 'plasma nitriding + oxidizing' will be called oxidized, and uncoated steel as the references.

In order to test and verify the effectiveness of these coatings in semi-in-plant condition, two novel technique were developed. The 'ease-of-release' test was employed to measure the adhesion between the coatings and the solidified aluminum [18]. And also accelerated immersion test was used to determine erosion/corrosion performance of coatings.

\section{Experimental setup}

\subsection{Materials and methods}

AISI H13 (1.2344) tool steel, as the die material, was used to manufacture test coupons Table 1. Then the specimens were machined in the annealed state to a round bar sample of $10 \mathrm{~mm}$ diameter as shown in Fig. 1. Specimens were vacuum heat treated (hardening at $1050^{\circ} \mathrm{C}, 5$ bar quenching in $\mathrm{N}$, double tempering at 550 and $595^{\circ} \mathrm{C}$, hardness 45-46 HRC) and then grinded, finished and polished to a surface roughness of $R_{a}=0.02 \mu \mathrm{m}$.

Plasma nitriding was applied as the first step in the duplex treatment with the following parameters: gas composition $\mathrm{N}_{2} / \mathrm{H}_{2}=10 / 90 \%$; pressure $300 \mathrm{~Pa}$; surface temperature $480^{\circ} \mathrm{C}$ and treatment time $8 \mathrm{~h}$. After plasma nitriding the functional surface of the pins was mechanically polished again to obtain a nitrided surface without

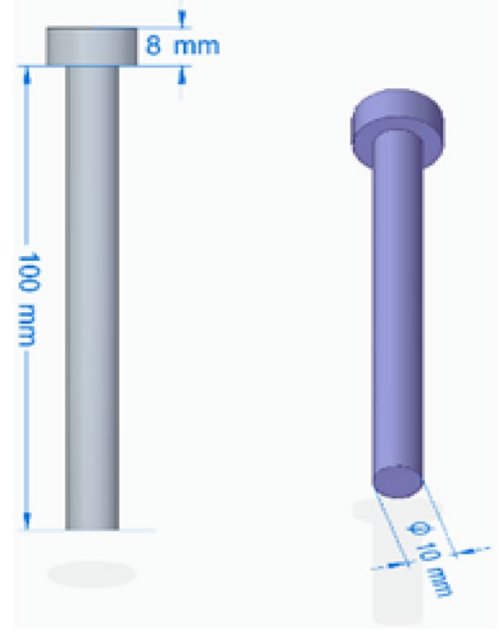

Fig. 1 Schematic and dimension of test coupons

the compound (white) layer using 1200 mesh Silicon carbide abrasive paper and diamond paste to reach the roughness of $R_{a}=0.02 \mu \mathrm{m}$. The deposition of PVD coatings directly onto the compound layer results in poor adhesion and spalling [19].

The nano-structural coatings were deposited using an industrial coating equipment by the means of vacuum cathodic arc evaporation (CAE). After cleaning in the water-based then in the alkaline soap solution and drying at $110^{\circ} \mathrm{C}$, the samples were mounted on rotating fixtures which were symmetrically placed around the cathode. For both NM and NC coatings, the main process parameters were as: substrate temperature of $350^{\circ} \mathrm{C}$ in a reactive Nitrogen atmosphere with gas pressure of $1.0 \times 10^{-3}$ $\mathrm{Pa}$, gas flow rate of $150 \mathrm{~cm}^{3} / \mathrm{min}$; arc current of $130 \mathrm{~A}$ and negative bias of -30 to $-200 \mathrm{~V}$.

The NC coating was deposited using a high purity cathodes of (99.95\%) TiAl alloy (50:50 at.\%) and Si (99.98\%). While for the NM coating, the deposition chamber was equipped with two cathodes made of high purity $\mathrm{Ti}$ (99.98\%) target and (99.97\%) Ti-Al alloy (63:37 at.\%). Two group of samples were deposited to the final layers of TiN and TiAIN as the working layers.

\subsection{Characterization}

The distribution of hardness in the nitriding layer was measured using Leitz Mini Load Vickers micro-hardness testing method using a load of $0.2 \mathrm{~N}$. The Nano-hardness
Table 1 Chemical composition of AISI H-13 tool steel (wt\%)

\begin{tabular}{lllllllll}
\hline Element & $\mathrm{C}$ & $\mathrm{Si}$ & $\mathrm{Mn}$ & $\mathrm{Cr}$ & $\mathrm{Ni}$ & $\mathrm{Mo}$ & $\mathrm{V}$ & $\mathrm{Fe}$ \\
\hline AISI H-13 & 0.38 & 1.3 & 0.6 & 5.2 & 0.3 & 1.75 & 1.2 & Bal \\
\hline
\end{tabular}


and Young's modulus of the coatings were measured by a nano Indenter system with the applied load of $5 \mathrm{mN}$ [20]. In order to avoid the substrate effect, the maximum indentation depth was set at $10 \%$ of the film thickness.

The thickness and morphology of coatings were determined in a fractured cross section of samples using a highresolution Philips XL 30 FEG SEM microscope, in a high vacuum, backscattered and secondary electron modes. This system was also equipped with an EDS-EDAX microprobe to obtain the chemical composition of the coatings.

$X$-ray diffraction patterns of coatings were recorded with the standard Bragg-Brentano geometry to examine films constitutive phases using Siemens D5000 X-ray diffractometer with Cu-Ka radiation $(\lambda=1.5405 \AA$ ). The Warren-Averbach method [21] was used to measure average TiAIN crystallite size and the lattice parameters.

The well-known Rockwell C (150 kgf) indenter adhesion test prescribed by the German Engineering Association (VDI 3198) norm was used to evaluate the adhesion quality of the coatings to the substrate [22]. The indentation effects on coatings such as cracks on coating surface and/ or presence of coating detachments around the indentation mark was scaled from HF1 (the best adhesion) to HF6 (the poorest adhesion). Results then were investigated using the SEM technique.

Surface topography and hence surface roughness $\left(R_{a}\right)$ of as-deposited samples were carried out using atomic force microscopy (AFM) in non-contact mode.

\subsection{Corrosion/erosion}

The dimensional change of the pin, corroded in aluminum melt, vary from location to location which makes it difficult to compare quantitative material loss of pins. Therefore, weight loss (WL) was selected to evaluate their washout resistance [23]. A dynamic liquid metal immersion experiment (Fig. 2) was carried out using a pedestal drill for the aim of holding, immersing and rotating the pins in the molten aluminum alloy $\mathrm{A} 384$ (Table 2 ) at $680^{\circ} \mathrm{C}$ for periods of $30,60,90$, and $120 \mathrm{~min}$ in a purpose designed furnace. For the duration of the test, each specimen was rotated at 400 RPM along its center axis to simulate high metal flow rate. This rotational speed was estimated to be equivalent to a gate velocity of $50 \mathrm{~m} / \mathrm{s}$ during aluminum $\operatorname{HPDC}[1,2]$.

After immersing the specimens in the molten aluminum alloy for a pre-determined time, they were taken out, cooled and cleaned in a $\mathrm{NaOH}$ alkaline solution for $5 \mathrm{~h}$ until all of the soldered aluminum was leached out from the pins' surface. The WL of the pins were measured with \pm 0.001 accuracy. Before weighing, the pins were cleaned with methanol and ethyl alcohol and dried with a heat gun. In addition, the percentage of soldered area (SA) was determined using optical photographs

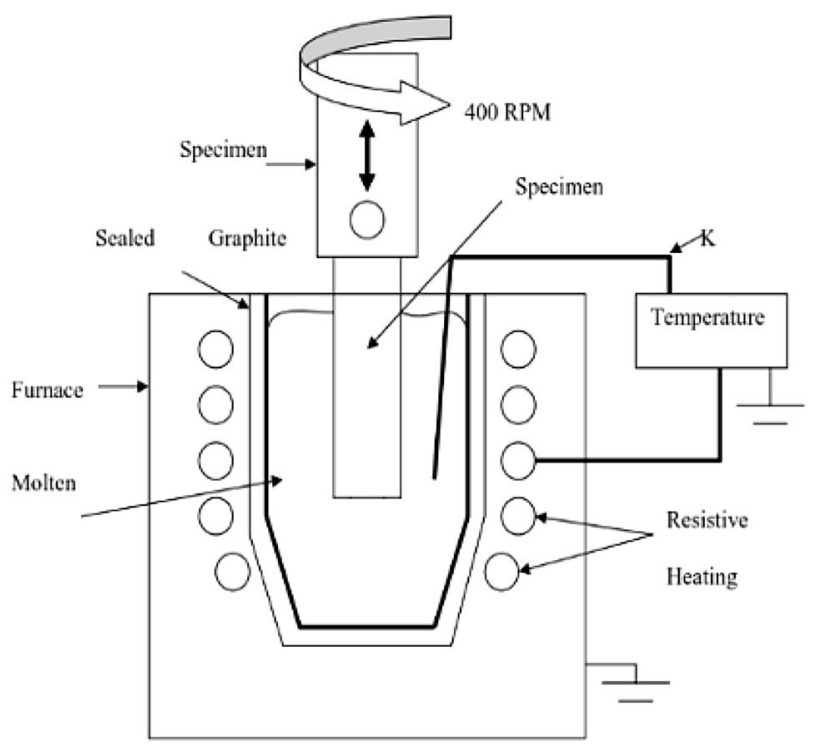

Fig. 2 The dynamic liquid metal immersion test configuration

Table 2 Chemical composition of A384 aluminum alloy wt $\%$

\begin{tabular}{llllll}
\hline Element & $\mathrm{Cu}$ & $\mathrm{Zn}$ & $\mathrm{Si}$ & $\mathrm{Mn}$ & $\mathrm{Al}$ \\
\hline A384 & 1.9 & 0.65 & 12.2 & 0.2 & $\mathrm{Bal}$ \\
\hline
\end{tabular}

and the computer image analysis system. This was performed after dipping test coupons in the molten aluminum for the duration of 10 up to $90 \mathrm{~s}$. Then surfaces were inspected to evaluate the formation of corrosion/ erosion regions using SEM and EDS analyses.

\subsection{Adhesion test}

The 'ease-of-release' was performed to compare surface adhesion and to measure the separation force of pins from aluminum casting. The test procedure was consisted of casting the molten aluminum alloy around the coated pins in a cylindrical mold at $680^{\circ} \mathrm{C}$ then pulling the pins out of the solidified casting. A mechanical tension testing machine with a fixture mounted on used to record the variation of pulling load versus pin displacement. The detailed test set-up and testing procedure is explained in the literature [18]. Figure 3 shows schematic 'ease-of-release' casting.

SEM microscopy was used in conjunction with the energy dispersive spectroscopy (EDS) to provide a semiquantitative analysis of tribological interaction between the coatings' surface and aluminum alloy after 'ease-ofrelease' test. 


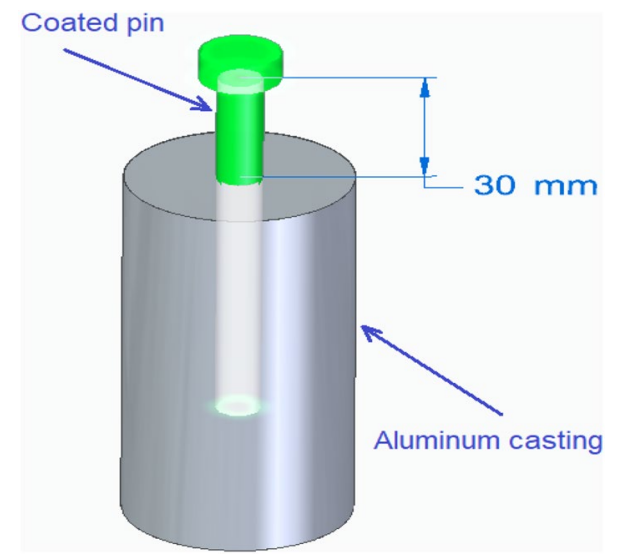

Fig. 3 The schematic figure of casted sample prepared for the 'ease-of-release' test

\section{Results and discussion}

\subsection{Hardness}

During the plasma nitriding process, a nitride layer of $150 \mu \mathrm{m}$ thick formed on the surface. Vickers micro-hardness measurements on cross-sectioned of the pins after plasma nitriding showed that the hardness was $1250 \mathrm{HV}$ at the surface and maintained $\sim 850 \mathrm{HV}$ for $50 \mu \mathrm{m}$ depth. As expected, there was a gradual hardness drop to the final substrate hardness. Nano-hardness values for NM coating were determined as $24 \mathrm{GPa}$ and Young's modulus of $214 \pm 8 \mathrm{GPa}$. These values were the same for both TiN and TiAIN working layers. The hardness of the TiAIN layer strongly depends on the Al content of the coatings [22]. The hardness of $38 \mathrm{GPa}$ and Young's modulus of $246 \pm 12 \mathrm{GPa}$ was measured for NC coating. The structure of NC coating consisted of nano-crystalline TiAIN embedded in the amorphous $\mathrm{Si}_{3} \mathrm{~N}_{4}$ matrix. This structure enables the coating to maintain the high hardness upon annealing up to $1100^{\circ} \mathrm{C}$ [24].

\subsection{Coatings adhesion}

The primary failure mechanism of PVD coatings is spalling under high stress due to lack of a strong adhesion between the coating and the substrate. This mode of failure becomes more severe due to a sharp hardness profile from the surface to the substrate. Nitriding layer not only provides a gradual change in hardness from the surface to the subsurface but also a better mechanical support for the PVD hard coating [25].

The appearances of Rockwell $C$ indentation mark on three coating systems are illustrated in Fig. 4. The indentation craters appeared on the surface of both coated samples revealed radial cracks at the perimeter of their

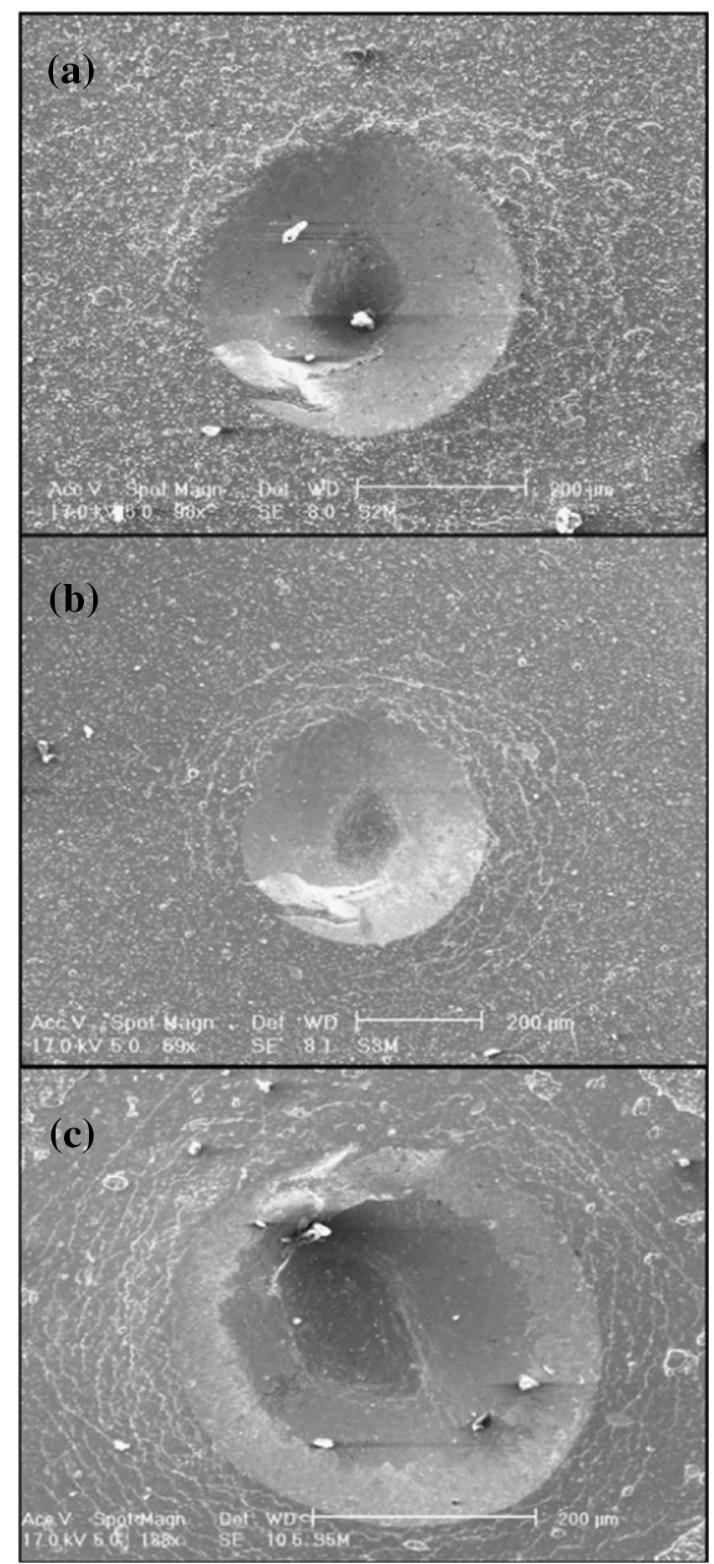

Fig. 4 SEM micrograph showing the indentation of VDI cohesion test on the surface of $\mathbf{a}$ NC, $\mathbf{b}$ NM-TiN, $\mathbf{c}$ NM-TiAIN

indentation. However, a small quantity of spots with flaking of delamination was visible in the case of NC film. Therefore, the adhesion quality of this layer is related to HF3 category according to VDI 3198 norm [22]. Since there is no appearance of detachments of the coating along the edge of the indentation and no branched cracks, the adhesion of NM coating evaluated to be HF2 and considered higher than that of NC coating. Namely, NM coatings have higher cracking resistance than the corresponding single layer coatings because cracks that tend to branch are deflected at the interfaces of a multilayer structure [12].

\section{SN Applied Sciences}




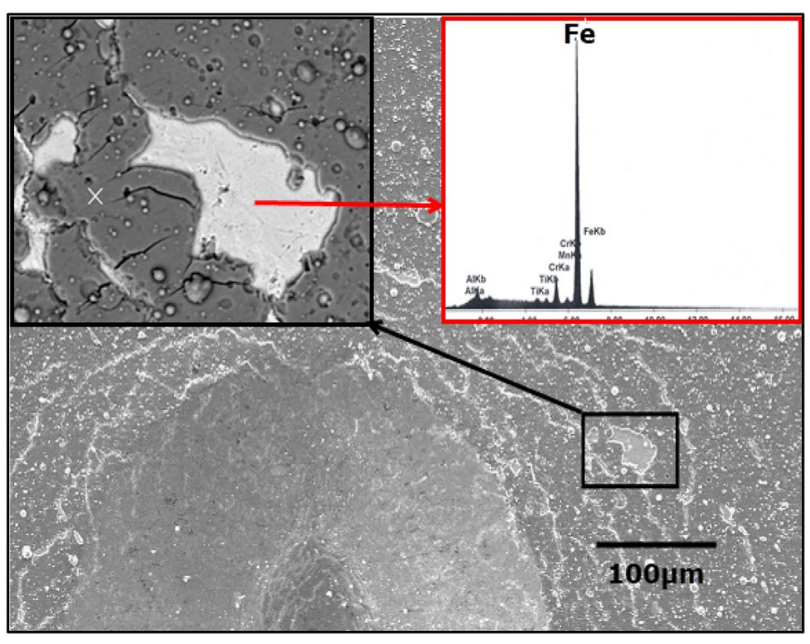

Fig. 5 SEM and EDS analyses of a spalling zone

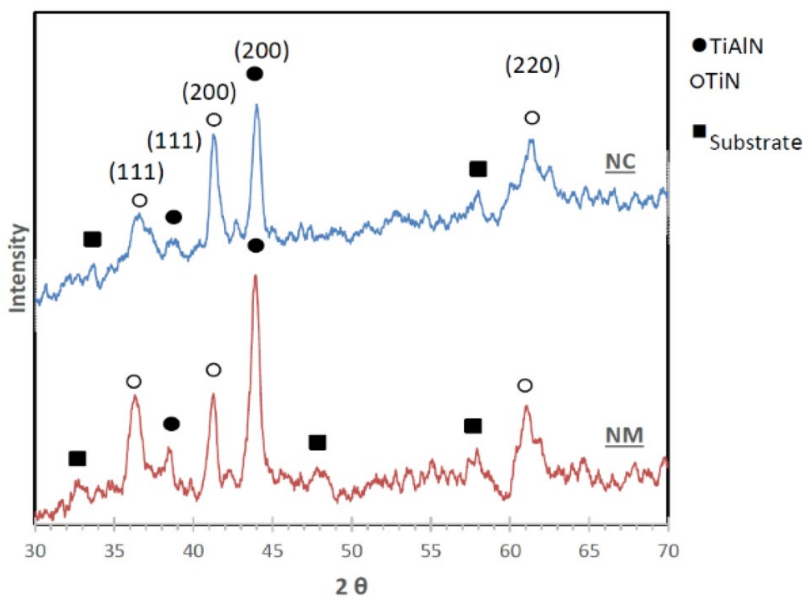

Fig. 6 The XRD patterns of the NC and NM films deposited on the steel substrate
After the adhesion test, the elemental analysis of a critical zone using an EDS probe in Fig. 5 showed the detected iron-rich points verifying a coating delamination effect.

\subsection{Surface analyses}

The X-ray diffraction patterns from the NM and NC coatings deposited on the steel substrate are shown in Fig. 6. The TiN and TiAIN layers were polycrystalline exhibiting diffraction peaks with the (111) and (200) and (111) and (220) preferred orientation, respectively. As it was expected, the diffraction lines of the TiAIN film are shifted towards higher Bragg angles as compared to the TiN lines. This happened due to the substitution of Ti atoms with $\mathrm{Al}$ atoms in the $\mathrm{B} 1-\mathrm{NaCl}$ structure of TiN which results in increased residual stresses in the coatings and decreased lattice parameter [15]. A similarity observed between XRD spectra of the NM and NC could indicate a structural identity of the TiAIN phase of both the coatings. The decrease in intensities of the (111) and (200) reflections in the NC coating shows an increase in the amorphous $\mathrm{Si}_{3} \mathrm{~N}_{4}$ content of coating. The average crystallite size of the regions of coherent scattering for the TiAIN phase, ranged from 10 to $12 \mathrm{~nm}$, indicating its nano-crystalline structure.

Figure 7a, b shows representative cross-sectional SEM micrograph for NM and NC coatings, respectively. The total coating thickness was measured to be $1.6 \mu \mathrm{m}$ for NM layer consisted of 18 alternating TiAIN/TiN layers applied on the pre-nitrided steel substrate. Whereas, the thickness of NC coating was measured to be $1.2 \mu \mathrm{m}$.

Figure 8a-c shows the SEM surface micrograph of ascoated NM coatings with TiN and TiAIN working layer and NC coating, respectively. Namely, thin films deposition by the cathodic arc evaporation (CAE) process leads to the formation of droplets on the top of the coated surfaces. The film with the larger size of droplets on the top was grown in the case of NM coatings with both TiN and TiAIN

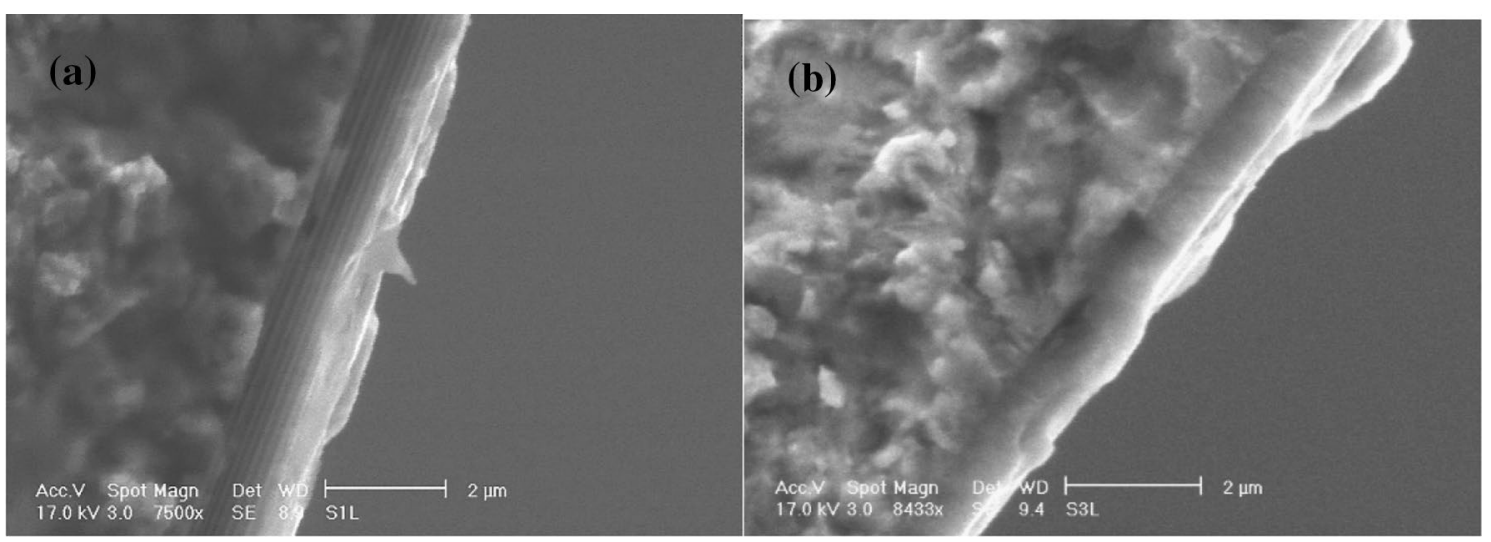

Fig. 7 Cross sectional SEM micrograph of $\mathbf{a}$ NM and $\mathbf{b}$ NC coating 


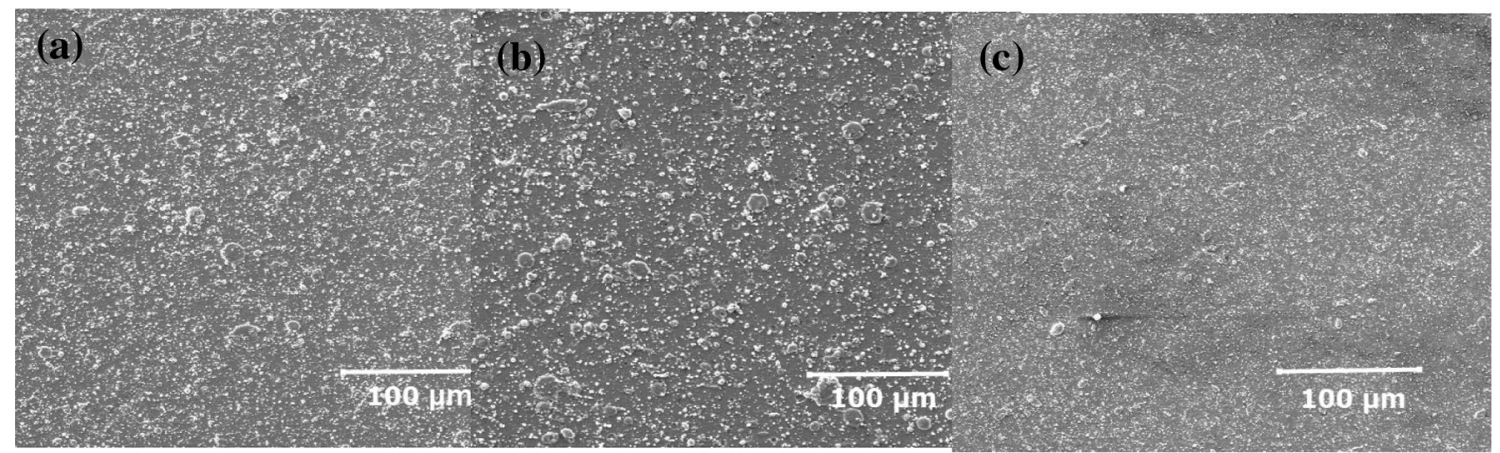

Fig. 8 surface micrograph of as-coated a NM-TiN, b NM-TiAIN, c NC coatings deposited by CAE technique

working layers. The melting point of $\mathrm{Al}$ is relatively low, in comparison with $\mathrm{Ti}$, therefore it could enhance a droplet formation. The use of these coatings for tribological applications requires grinding and polishing after deposition to remove droplets. It can be seen that the NC coating surface was much smoother than those of NM coatings, showing fewer white particles on it. An increase in the number of defects, on the top of the coatings, could activate localized corrosion.

\subsection{AFM}

The AFM three-dimensional micrograph illustrating the surface topography of the NM-TiAIN, NM-TiN, and NC coatings are shown in Fig. 9a-c, respectively. Evaluation of surface morphology revealed a columnar nature of the layer microstructure for both NM coatings. The average roughness $\left(R_{a}\right)$ of the NM-TiAIN and NM-TiN working layers were $3.8 \mathrm{~nm}$ and $3.3 \mathrm{~nm}$, respectively. This value for the NC coating was measured to be $2.6 \mathrm{~nm}$. The addition of the crystalline TiAIN in the amorphous $\mathrm{Si}_{3} \mathrm{~N}_{4}$ matrix is known to change the surface morphology from a columnar microstructure to a dense structure [15]. The size of grains on the NM films was approximately $20 \mathrm{~nm}$. In Fig. 1c, the obvious sharp-island shape is present in the case of NC. Upon The measurement of the grain size of $12 \mathrm{~nm}$, confirmed the value calculated from XRD patterns.

\subsection{Adhesion/wettability}

Wettability of different PVD coatings using the sessile drop laboratory tests have been investigated and reported in pervious researches $[18,26]$. However, the test by which candidate coatings can undergo a semi-in-plant examination rarely developed. The 'ease-of-release' experimental set-up provides direct line-of-sight allowing to examine of soldering and to measure the wettability and adhesive tendency of the casting toward the pin surface [18]. During the test, pins are subjected to a high friction force. Figure 10 exhibits the load versus the displacement curves of the six coatings system after applying the easeof-release test. The maximum point of each curve is the critical load for release of the pin from the aluminum cast. These critical loads represent the adhesion/wettability force between the coating and the aluminum.

The higher critical load, the better wettability of the coating. The area under each curve is related to the adhesion energy between the coating and the solid aluminum which can be divided into two parts. The area from the start to the critical load is the adhesion energy, while the area between the critical load to the end relates to the friction energy [18]. It is obvious that the uncoated sample the highest and the oxidized coating exhibits the lowest critical load comparing with the other four coatings. This quality of oxidized sample can be attributed to low wettability and friction coefficient nature of magnetite, i.e. $\mathrm{Fe}_{3} \mathrm{O}_{4}$ film which prevents the formation of intermetallic phases and provides solid-lubricating to a great extent $[27,28]$. Figure 10 also demonstrates the critical load and friction energy of the NC coating which were much lower than that of the other samples. It can be related to the lower roughness of the friction surface and crystal grain size. This behavior is also related to the presence of the Si content in the coatings as reported in Al-Ti-Si-N based nanocomposite systems [16]. The coatings of such structure are able to maintain a low friction coefficient (self-lubricating coatings) in extreme environments, combined with high hardness to improve the mechanical resistance [29]. Despite its relatively high surface roughness, NM-TiAIN presented lower critical load and friction energy in comparison to smoother NM-TiN layer. It can be explained by the presence of $\mathrm{Al}$ as a substitute for $\mathrm{Ti}$ atoms in the TiN crystalline structure which forms a high oxidation resistant, low friction, and wettability $\mathrm{Al}_{2} \mathrm{O}_{3}$ layer on top of coating surface [30]. Nitriding treatments also slightly improved tribological properties and wettability of $\mathrm{H}-13$ steel. This is consistent with the findings reported concerning that thermochemical treatments such as nitriding can retard 

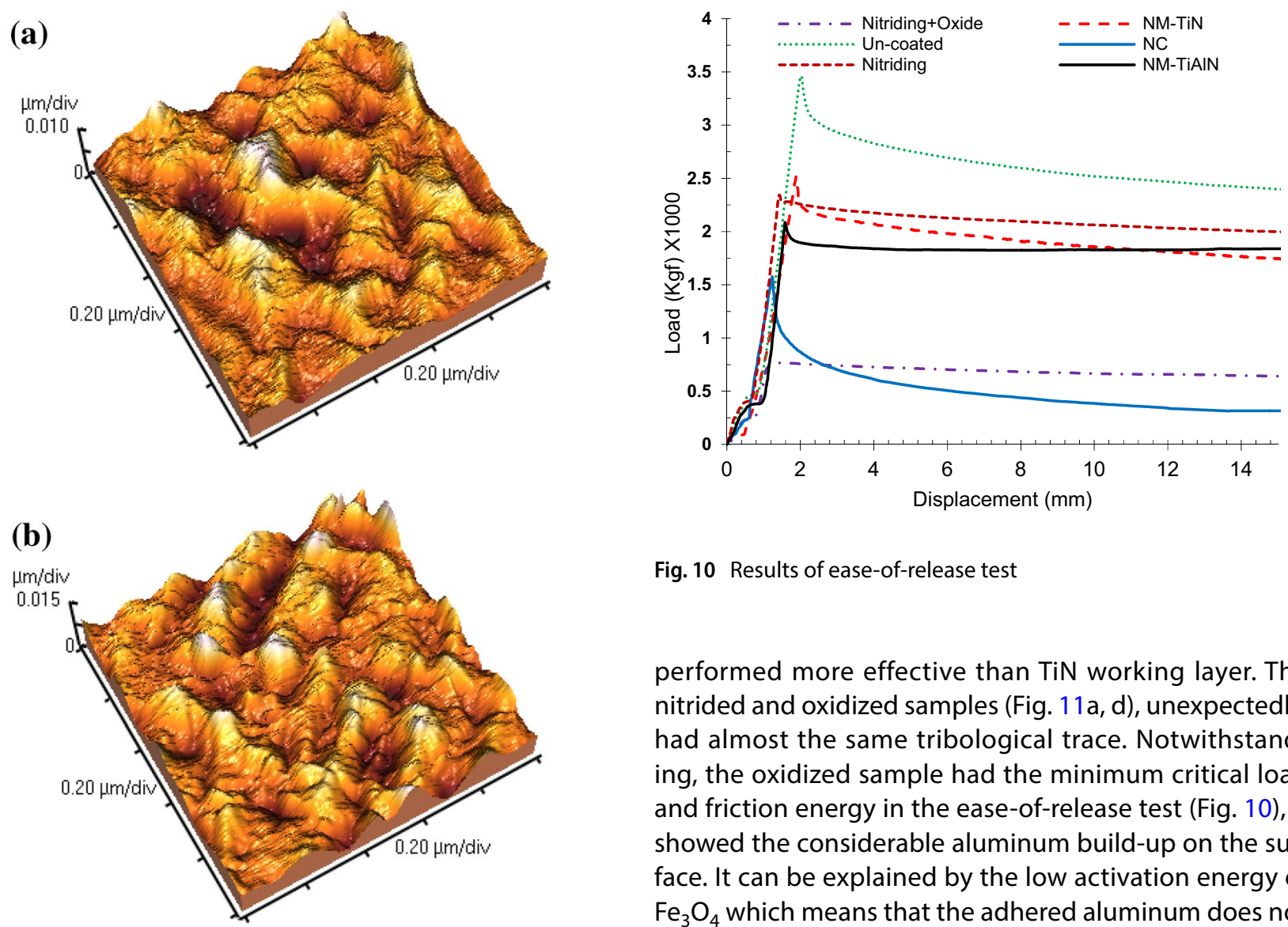

Fig. 10 Results of ease-of-release test

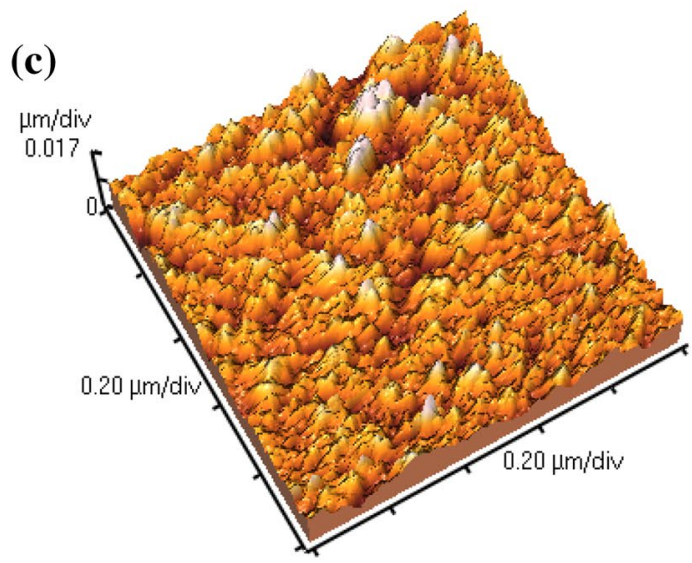

performed more effective than TiN working layer. The nitrided and oxidized samples (Fig. 11a, d), unexpectedly, had almost the same tribological trace. Notwithstanding, the oxidized sample had the minimum critical load and friction energy in the ease-of-release test (Fig. 10), it showed the considerable aluminum build-up on the surface. It can be explained by the low activation energy of $\mathrm{Fe}_{3} \mathrm{O}_{4}$ which means that the adhered aluminum does not to react and create chemical bond with the surface. During the test, these built-up materials can easily separate from the surface and results in low critical load. Therefore, what is seen on the tribological surface is only a smooth and very thin trace of aluminum coverage called cold soldering. The uncoated sample was thoroughly covered with aluminum layer bonded on the steel surface explaining its highest critical load among the other samples.

\subsection{Soldering}

Optical examination and image analysis of the coating systems revealed that the uncoated specimen after the immersion for $30 \mathrm{~s}$ in the molten aluminum alloy was severely affected by soldering over its entire area (Fig. 12). It was assumed that soldering started on bare steel surface immediately on contact with the molten aluminum alloy also reported by Han et al. [31]. While, For the same immersion duration, the surface of NM-TiN, NM-TiAIN, and NC coatings covered with respectively 20 , 10 , and $5 \%$ of soldered area. In the other word, $20 \%$ of surface coverage with aluminum, took place respectively after 50 and $30 \mathrm{~s}$ of exposure for NM-TiAIN and NM-TiN coatings, while, the NC coated sample resisted up $90 \mathrm{~s}$. The oxidizing treatment protected samples slightly better than that of nitrided sample due to the presence of 


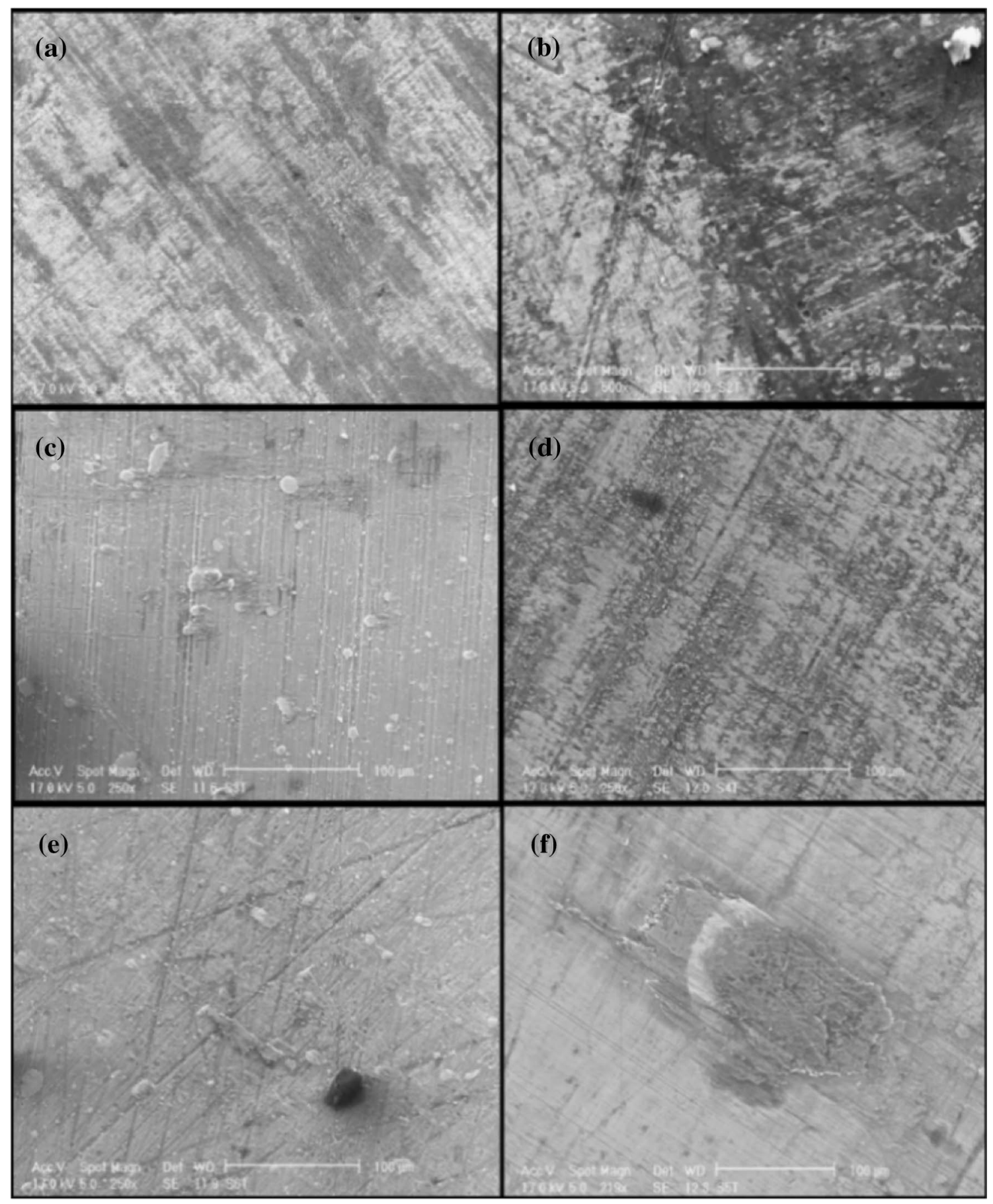

Fig. 11 The tribological trace of coatings after ease-of-release test, a oxidized, b NM-TiN, c NM-TiAIN, $\mathbf{d}$ nitrided, e NC, $\mathbf{f}$ uncoated

protective oxide layer. As mentioned above, the native film composed of the iron-oxide $\left(\mathrm{Fe}_{3} \mathrm{O}_{4}\right)$, layer produced on steel sample provides protection against further solder formation. However, if the temperature of a die surface exceeds $560{ }^{\circ} \mathrm{C}$, then the oxide FeO forms at the metal interface and the rate of soldering increases dramatically [32].

\subsection{Washout}

The results of accelerated corrosion/erosion test are summarized in Fig. 13 as weight loss (WL) versus dipping time. In this figure, the result of uncoated steel was omitted due to a higher WL range making it incomparable with the coated samples in the same graph. The results presented

\section{SN Applied Sciences}




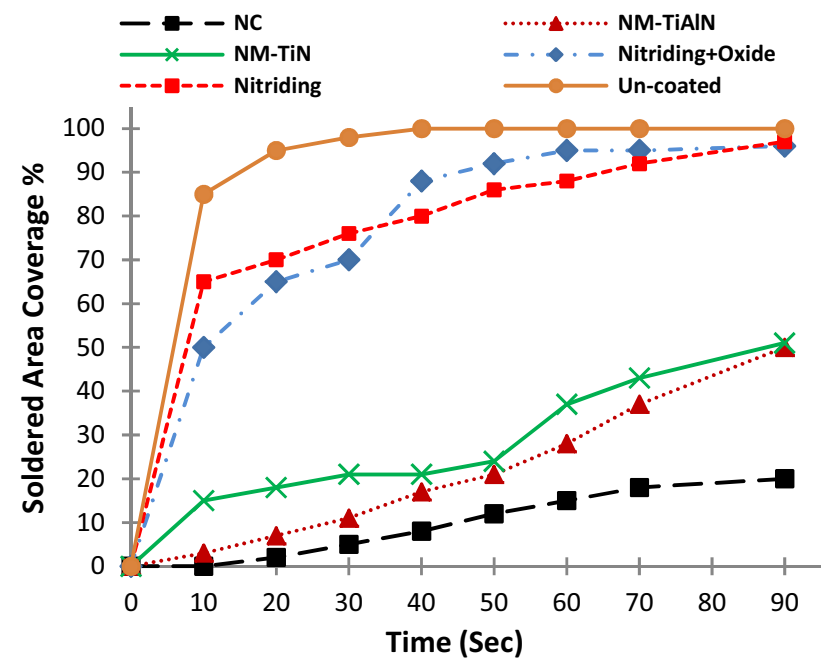

Fig. 12 Percentage of soldered area coverage (SA)

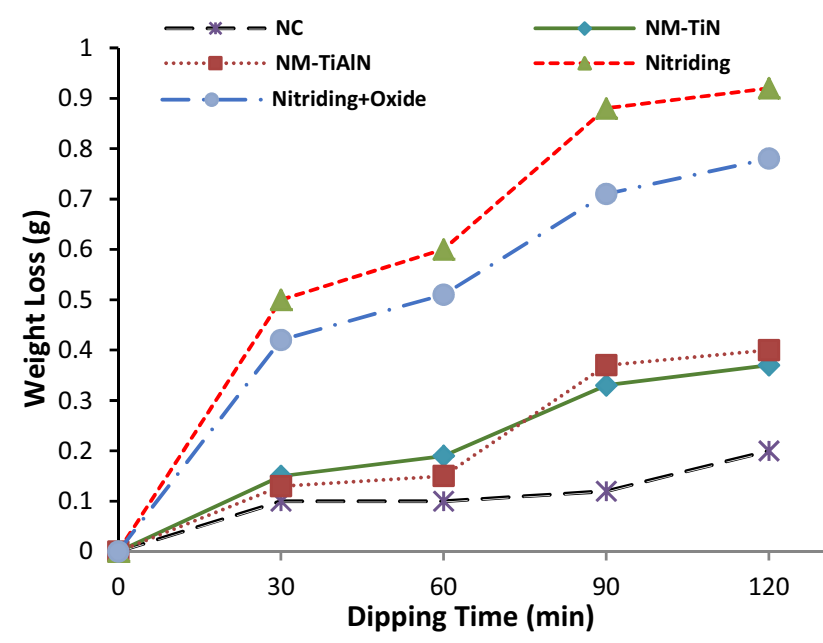

Fig. 13 Weight loss of pins versus immersion time

in this figure show that erosion/corrosion, defined as washout, can be declined in the early stages of immersion test by the utilizing of PVD nano-structural coatings. Similar results have been reported by other researcher [4]. It is seen that both NM-TiN and NM-TiAIN layers significantly decreased the $\mathrm{WL}$ of the $\mathrm{H} 13$ pin up to 1 -h exposure in comparison with nitrided and oxidized pins. As expected, TiAIN working layer protected steel against corrosion/erosion attack slightly better than TiN layer due to a higher thermal stability. Both NM-TiN and NM-TiAIN coatings provided the same level of protection. While the NM coatings outperformed the nitrided and oxidized samples in resistance to washout, they failed to maintain their corrosion/ erosion resistance for a longer period of test ( $>60 \mathrm{~min}$ ). However, NC coating held up the best and hindered WL of steel substrate up to $90 \mathrm{~min}$ of immersion and rotating in aluminum alloy. Both the densification effect and reduced crystallite size, hence high hardness of NC coating are believed to be responsible for enhanced corrosion/erosion behavior of the coating. A dense micro-structure in case of NC coatings prevents the diffusion of the corrosive medium into the substrate. Furthermore, the addition of Al to transition metal nitrides improves the corrosion resistance by the formation of a passive $\mathrm{Al}_{2} \mathrm{O}_{3}$ layer on the surface of the coating during chemical attack $[16,33]$. This prevents the coating from further failure.

As mentioned above, in some of PVD deposition processes including CAE, small particles of the target metal could be embedded in the coating (Fig. 8). These particles can be dissolved or removed by the molten metal and led to formation of a weak sites where pitting may occur (Fig. 14). These pits also can initiate via cracks in the coating. Penetrating under the coating through these pits, aluminum starts to dissolve the underlying substrate as a form of high-temperature corrosion and to form $\mathrm{Fe}-\mathrm{Al}-\mathrm{Si}$ intermetallic phases as soldering. Furthermore, the reactions of formation of these intermetallic phases are exothermic and the heat generated from these reactions will increase the kinetics and the rate of chemical attack [32]. Therefore, the damaged area increases gradually all over the surface by developing new sites and merging of the pitting areas.

Figure 14 shows the typical appearance of pitting damage of the six coatings system after $60 \mathrm{~min}$ of washout test. These pits are randomly dispersed in the specimen and the size of the cones increased over time. Erosion first appears as small pits then gradually the size of pits increases until it develops into a rough surface [14]. For the NM-TiN pin, the film remained on the substrate, although many corrosion pits were observed. For the NM-TiAIN, a similar corrosion pits were observed, although the number of the pits were smaller than that of the NM-TiN working layer. On the contrary, for the NC-coated pin, the pitting corrosion was scarcely observed which is attributed to few pinholes on the films and exceptional high temperatures stability.

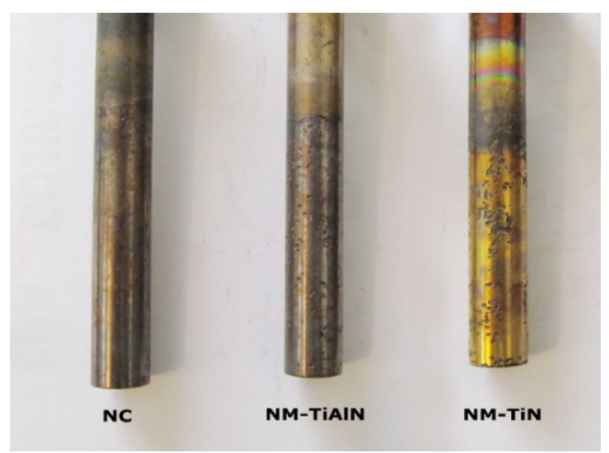

Fig. 14 Aluminum corrosion pitting on PVD coatings 


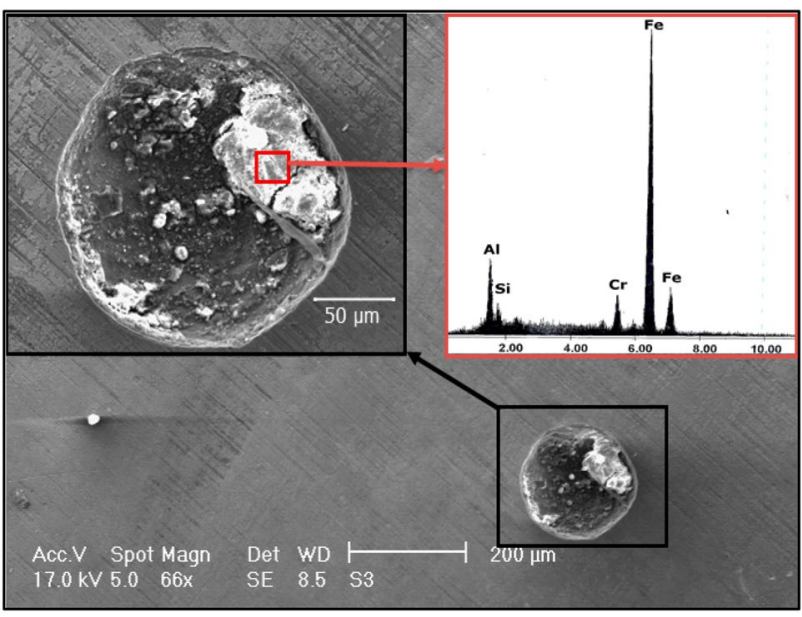

Fig. 15 A corrosion pit, the attacked zones in which intermetallic compounds form

In Fig. 15 the SEM examination of a pitting zone at a higher magnification illustrated presence of soldered materials within the pits. Using EDS elemental analysis, determined the compounds comprised of $\mathrm{Si}, \mathrm{Al}$, and Fe. Structural analysis of soldering, which was investigated in previous works $[7,13]$, have shown three distinct layers consisted of $\mathrm{Fe}-\mathrm{Al}-\mathrm{Si}$ intermetallic phases.

\section{Conclusion}

- It was found that nanostructural coatings not only act as a physical and chemical barrier to preventing atomic diffusion and intermetallic phase formation but also reduce wettability and adhesion between steel and molten aluminum alloy.

- PVD coatings, however, contain pits, holes and defects thereby allowing direct contact between the molten aluminum alloy and the steel substrate, thus exposure to the failures of corrosion/erosion and soldering limited to those defective sites. Suitable coatings' practices are essential in ensuring a high performance PVD coating.

- Based on the quantities achieved from weight loss and percentage of soldered area and the quality of corrosion marks in the form of pitting in pin surface, the nanocomposite coating had the best washout and soldering resistance, followed by nano-multilayer coating with TiAIN and TiN working layers, oxidized, nitrided, and uncoated $\mathrm{H}-13$ steel. Also, a higher reduction in erosion was seen in the case of nanocomposite coating.

- The accelerated soldering and washout testing techniques are needed for further developments to offer more accurate and near-practical results in aluminum die-casting.

- In general, soldering is a short-term phenomenon because soldering will be formed on the die surface onset of exposure to aluminum melt. On the contrary, washout is a long-term phenomenon whereas an obvious washout will occur after atomic diffusion which takes time.

Acknowledgements Authors would like to thank Mehran Gorbandoost the CEO and Kiavash Pajohesh the CFO of Iran Radiator for their valuable technical and financial supports.

\section{Compliance with ethical standards}

Conflict of interest On behalf of all authors, the corresponding author states that there is no conflict of interest.

\section{References}

1. Gulizia S, Jahedi MZ, Doyle ED (2001) Performance evaluation of PVD coatings for high pressure die casting. Surf Coat Technol 140:200-205

2. Yan M, Fan Z (2000) The erosion of $\mathrm{H} 21$ tool steel in molten $\mathrm{A} 380$ alloy. Mater Sci 35:1661-1667

3. Sundqvist M, Bergström J, Björk T, Westergård R (1997) Corrosive wear of duplex coatings in die casting of aluminum. In: Transactions, 19th international die casting congress and exposition, Minneapolis, p 325

4. Aharonov R, Chellapilla S, Janoss B, Shivipuri R, Lakare A (1999) An investigation of the corrosion of $\mathrm{H} 13$ steel coated with $\mathrm{CrN}$ in molten aluminium alloy: effects of surface preparation and coating thickness. In: Transactions, 19th international die casting congress and exposition, T99-113

5. Srivastara Joshi V, Shivpuri R, Bhattacharya R, Dixit S (2003) A multilayer coating architecture to reduce heat checking of die surfaces. Surf Coat Technol 163-164:631-636

6. Hairy P, Richard M (1997) Reduction of sticking in pressure die casting by surface treatment. In: Transactions, 19th international die casting congress and exposition, Minneapolis, p 307

7. Shankar S, Apelien D (1997) Die soldering a metallurgical analysis of the molten aluminium/die interface reaction. In: Transactions, 19th international die casting congress and exposition, T97-085

8. Han Q, Viswanathan S (2003) Analysis of the mechanism of die soldering in aluminum die casting. Metall Mater Trans $A$ 34A:139-146

9. Pogrebnyak AD, Shpak AP, Azarenkov NA, Beresnev VM (2009) Structures and properties of hard and superhard nanocomposite coatings. Phys Uspekhi 52:29

10. Wadsworth I, Smith IJ, Donohue LA, Münz W-D (1997) Thermal stability and oxidation resistance of TiAIN/CrN multilayer coatings. Surf Coat Technol 94-95:315-321

11. Musil J (2012) Hard nanocomposite coatings: thermal stability, oxidation resistance and toughness. Surf Coat Technol 207:50-65

12. Vereschaka AA, Grigoriev SN (2017) Study of cracking mechanisms in multi-layered composite nano-structured coatings. Wear 378-379:43-57 
13. Shankar S, Apelian D (2002) Die soldering: mechanism of the interface reaction between molten aluminum alloy and tool steel. Metall Mater Trans B 33B:465-476

14. Gopal S, Lakare A, Shivpuri R (2000) Soldering in die casting: aluminum alloy and die steel interactions. Die Cast Eng 44:70-81

15. Barshilia Harish C, Rajam KS, Jain A, Gopinadhan K, Chaudhary $S$ (2006) A comparative study on the structure and properties of nanolayered TiN/NbN and TiAIN/TiN multilayer coatings prepared by reactive direct current magnetron sputtering. Thin Solid Films 503:158-166

16. Barshilia Harish C, Deepthi B, Rajam KS (2006) Deposition and characterization of TiAIN $/ \mathrm{Si}_{3} \mathrm{~N}_{4}$ superhard nanocomposite coatings prepared by reactive direct current unbalanced magnetron sputtering. Vacuum 81:479-488

17. Eh Hovsepian P, Munz WD (2003) Recent progress in large-scale production of nanoscale multilayer/superlattice hard coatings. Vacuum 69:27-36

18. Moore JJ, Lin J, Carrera S, Kunrath AO, Myers S, Mishra B, Ried $P$ (2006) Design methodology for optimized die coatings used in aluminum pressure die casting. Surf Coat Technol 201(6):2930-2941

19. Sun Y, Bell T (1992) Combined plasma nitriding and PVD treatments. Trans Inst Met Finish 70(1):38-44

20. Barshilia HC, Surya Prakash M, Sridhara Rao DV, Rajam KS (2005) Superhard nanocomposite coatings of TiN/a-C prepared by reactive DC magnetron sputtering. Surf Coat Technol 195:147

21. McKeehan M, Warren BE (1953) X-ray study of cold work in thoriated tungsten. J Appl Phys 24:52

22. Verein-Deutscher-Ingenieure (1992) Daimler Benz adhesion test, VDI 3198. VDI-Verlag, Dusseldorf, $p 7$

23. Shivpuri R, Chu Y-L, Venkatesan K (1996) An evaluation of metallic coating for erosive wear resistance in die casting applications. Wear 192:49-55

24. Veprek S, Jilek M (2002) Super- and ultrahard nanocomposite coatings: generic concept for their preparation, properties and industrial applications. Vacuum 67:443-449
25. Sokovic M, Panjan P, Cekada M (2006) Improvement of tool life of die-casting tools with duplex treatment. Int J Microstruct Mater Prop 1(2):231-240

26. Kearns K (2002) Determination of interactions between molten aluminum and selected die coatings for aluminum die casting. Colorado School of Mines, pp 54-58

27. Clark WT, Pritchard C, Midgley JW (1967) Mild wear of unlubricated hard steels in air and carbon dioxide. In: Proceedings of the Institution of Mechanical Engineers, conference proceedings, vol 182, pp 97-105

28. Fraser D, Jahedi M (2000) Magnetite coating for prevention of soldering in aluminum HPDC tooling. Die Casting Engineer, March/April, pp 96-100

29. Yu D, Wang C, Cheng X, Zhang F (2009) Microstructure and properties of TiAISiN coatings prepared by hybrid PVD technology. Thin Solid Films 517:4950-4955

30. Riedl A, Schalk N, Czettl C, Sartory B, Mitterer C (2012) Tribological properties of $\mathrm{Al}_{2} \mathrm{O}_{3}$ hard coatings modified by mechanical blasting and polishing post-treatment. Wear 289:9-16

31. Han Q, Xu H, Ried PP, Olson P (2010) Accelerated method for testing soldering tendency of core pins. Int J Cast Met Res 23(5):296-302

32. Carrera S, Moore JJ, Kearns K, Salas O, Mishra B (2001) The development of a surface engineered coating system for aluminum pressure die casting dies. In: Die casting congress and exposition

33. Cunha L, Andritschky M, Rebouta L, Pischow K (1999) Corrosion of $\mathrm{CrN}$ and TiAIN coatings in chloride-containing atmospheres. Surf Coat Technol 116-119:1152

Publisher's Note Springer Nature remains neutral with regard to jurisdictional claims in published maps and institutional affiliations. 